\title{
Sustainability in Cereal Crop Production in Mediterranean Environments
}

\author{
Michele Perniola, Stella Lovelli, Margherita Arcieri, and Mariana Amato
}

\begin{abstract}
The continuous increase of the world population (a growth of about onethird is expected by 2050), together with an even larger increase in food demand (especially in emerging countries), will lead in the next 30 years to the necessity to produce $70 \%$ more food. To keep the pace with food demand, global cereal production would need to increase by $40 \%$ overall, or by some 900 million tons between the present and 2050. Single countries can either increase production or increase net imports or a combination of both.

This new global emergency involves researchers, farmers, politicians, the agrofood industry, and all stakeholders, and the new challenge can be summarized as follows: to produce more, but in a sustainable way. The goal of "sustainable intensification" constitutes one of the priorities for the research in agriculture and one of the cornerstones of the new Common Agricultural Policy. In this context, all the techniques designed to maximize production through the more efficient use of resources are in line with the objectives of sustaining production with minimal impact.
\end{abstract}

In Mediterranean environments, cereal crops are grown mainly in the semiarid and subhumid areas. In arid and semiarid areas dryland farming, techniques are of renewed interest in the view of sustainability. They are aimed to increase water accumulation in the soil, reduce runoff and soil evaporation losses, choose species and varieties able to make better use of rainwater, and rationalize fertilization plans, sowing dates, and weed and pest control.

Fertilization plans should be based on well-defined principles of plant nutrition, soil chemistry, and chemistry of the fertilizer elements. Starting from the calculation of nutrient crop uptake (based on the actually obtainable yield), dose calculation must be corrected by considering the relationship between the availability of the trace elements in soil and the main physical and chemical parameters of the soil $(\mathrm{pH}$, organic matter content, mineralization rate, $\mathrm{C} / \mathrm{N}$, ratio of solubilization of phosphorus, active lime content, presence of antagonist ions, etc.).

M. Perniola $(\bowtie) \cdot S$. Lovelli • M. Arcieri • M. Amato

School of Agriculture, Forestry, Food and Environmental Science, University of Basilicata, Viale dell'Ateneo Lucano 10, Potenza, Italy

e-mail: perniola@unibas.it; stella.lovelli@unibas.it; margherita.arcieri@gmail.com; mariana. amato@unibas.it 
The choice of traditional, minimum, or no-tillage is one of the most controversial aspects of agricultural research; much depends on soil texture, crop type (depending mainly on the characteristics of the root), rainfall regime (mainly intensity), longperiod tillage plan, structural stability of the soil (in function of the organic matter content), and all other variables and their interaction. In any case, minimum tillage and sod seeding are generally less expensive and evidence points to a lower production of $\mathrm{CO}_{2}$ with respect to traditional tillage.

Weed and pest control is also a critical point for the sustainability of cereal production: sustainability in control strategies involves minimizing the use of chemicals while safeguarding yields. To this end, priority should be given to preventive and nonchemical agronomic measures, while chemical means should be used only when the level of weeds and pests exceeds the threshold of economic damage.

Finally, precision farming is one of the most powerful tools for the sustainability of cereal crop production. This technique helps the farmers in their decisions, taking into account the local variability of physical, chemical, and biological properties of the soil, as well as the timing of input application. With this management strategy, input of resources is balanced and optimized in order to increase yields and reduce interventions and costs; the environmental impact is significantly reduced, as well as the amount of resources used for the production.

\section{Introduction}

The continuous increase of the population (worldwide a growth of about one-third is expected by 2050), together with an even larger increase in food demand (especially in emerging countries), will lead in the next 30 years to the necessity to produce $70 \%$ more food to keep pace with the demand (FAO 2013).

Worldwide, cereals represent the main agricultural staple food; more than $50 \%$ of the daily energy intake is accounted for by cereals (FAO 2014b). Overall, cereal production has followed the trend of increasing food demand in the past, and according to the High-Level Expert Forum, this trend is expected to continue in the future (Fig. 1).

To keep the pace of food demand, global cereal production would need to increase by $40 \%$ overall, or by some 900 million tons between the present and 2050. Single countries can either increase production or net imports or a combination of both. As shown in Fig. 1, cereal production is increasing more in developing countries, to sustain their own demand; anyway it is not excluded that export of cereal commodities from developed countries will be necessary to meet the needs of developing countries. Wheat is the main food grain in Western countries; Europe, Central Asia, and the Russian Federation are the main wheat producers, with a huge yield per hectare variability as a function of environmental conditions 


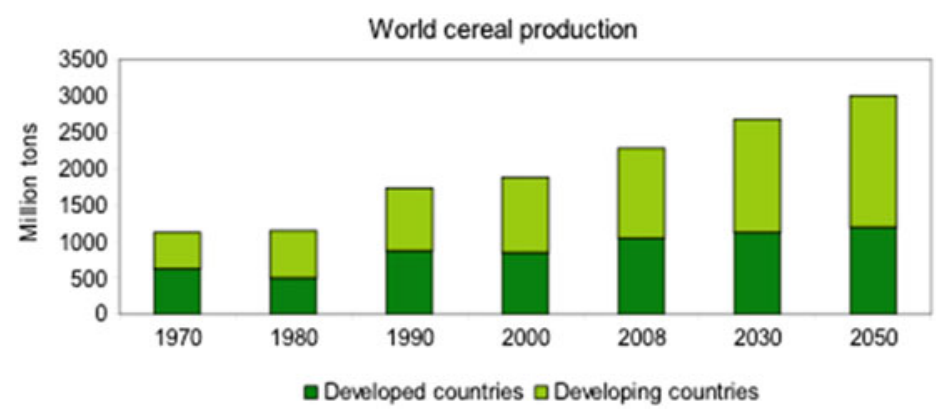

Fig. 1 Trend of world cereal production (High Level Expert Forum 2009)

and farming practices: generally yields range from $9 \mathrm{t} / \mathrm{ha}$ in the more favorable environment and intensive farming practice to less than $1 \mathrm{t} / \mathrm{ha}$ in less favorable conditions.

After a large increase from the beginning of the nineteenth century until the Green Revolution years, in recent years growth rates of cereal yields have slowed down in many countries; namely, growth rates of $6 \%$ were calculated in 1960, but they gradually dropped to $1.5 \%$ in 2000 (Fig. 2). While a constant increase in productivity growth rate is limited by the physiological limits of plant production, many other causes led to the above said reduction: among these the shift to less intensive farming practice due to environmental issues, a lower investments in agricultural research and development, and the adverse effects of climatic changes.

Increases in food production can be achieved by changing soil use from natural to agricultural land; this is not a viable option in general, considering the relatively low surface of natural land and its important role in the ecological equilibrium of the planet.

At the same time, agricultural land has been steadily decreasing due to overbuilding, desertification, erosion, salinization, change of use, and abandonment of marginal lands; in Italy in the last 3 years, $7.3 \%$ of the arable land was lost due to a combination of these destinations (ISPRA 2014). It is not surprising, then, that agricultural production no longer keeps up with the food demand since 1990. The result is a significant increase in food costs (FAO 2014a).

This new global emergency involves researchers, farmers, politicians, the agrofood industry, and all stakeholders, and the new challenge can be summarized as follows: to produce more, but in a sustainable way. The goal of "sustainable intensification" constitutes one of the priorities for the research in agriculture and one of the cornerstones of the new Common Agricultural Policy.

About $26 \%$ of worldwide agricultural land is grown under irrigation, mostly used for high-value crops such as fruits and vegetables, and produces $40 \%$ of food needs. The yield recorded in these areas has achieved in recent years $80 \%$ of the maximum potential yield (World Bank 2008). A relatively low margin remains then for a further increase of production in irrigation regime. 


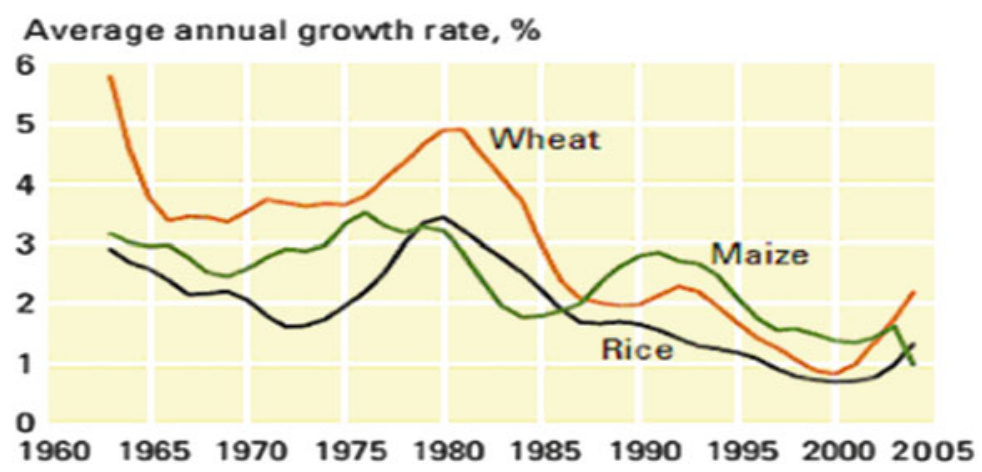

Fig. 2 Annual average growth rates of cereal yields [Source: World Bank (2008)]

The remaining $74 \%$ of agricultural crops worldwide are grown in rainfed conditions, generally in semiarid environments, where $60 \%$ of food and feed, such as cereal and fodder crops (Birard et al. 2009), are produced.

As opposed to what happens in the irrigated areas, the average production in dryland is well below the maximum potential yield (Passiura and Angus 2010). It is generally thought that the limiting factor in rainfed areas is the scarce water availability. Nevertheless, from the analysis of data obtained in a large body of research on wheat (reported in Fig. 3), it turns out that yields are generally lower than those potentially obtainable even at the level of water availability during the whole cropping cycle.

Indeed, besides water scarcity, other factors interact to limit crop production (Angus and van Hearwardeen 2001; Grassini et al. 2009). Some of these include planting date, weed competition, pathogen attacks, nutritional deficiencies, abnormal edaphic conditions, and high and low temperatures.

In this context, all the techniques designed to maximize production through the more efficient use of resources are in line with the objectives of "sustainable intensification." In Mediterranean environments, cereal crops are grown mainly in the semiarid and subhumid areas; in arid and semiarid areas, dryland farming is of renewed interest in the view of sustainability. It consists of a series of techniques aimed to increase the water accumulation in the soil, reduce runoff and soil evaporation losses, and choose species and varieties able to make better use of rainwater and, eventually, of supplementary irrigation.

Dryland farming has to be reconsidered also in view of the effects of climate change on cropping systems; in this context, new approaches need to be developed and evaluated on a series of issues such as the rational use of windbreaks, fertilization, irrigation scheduling in situations of "deficit irrigation," and the latest techniques for weed control, planting density, and planting dates for the newer varieties.

Within this framework the next few paragraphs will address the main aspects of cropping technique aimed at the sustainability of cereal production in Mediterranean environments. 
Fig. 3 Schematic representation of wheat yield in relation to seasonal water supply. The solid line depicts yield if water is the only limitation. The points cover the range of farmers' experience and are typically below the solid line because of yield limitations due to factors other than water such as weeds, diseases, poor nutrition, frost, and other problems (from Passiura and Angus 2010)

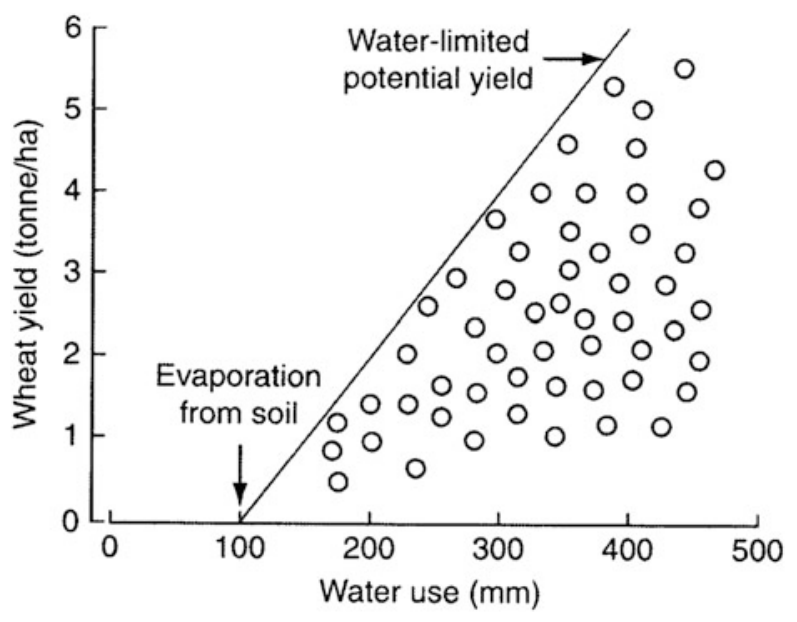

\section{Soil Fertilization}

Soils of the arid and semiarid environments are generally characterized by a limited content of organic matter and macronutrients such as nitrogen and phosphorus. It is well known, however, that the availability of these elements strongly affects the crop productivity and food quality. Therefore in dry farming, organic and mineral fertilization must be carefully considered, since they represent the cropping technique which allows a direct control of the quantitative and qualitative crop response. As for organic fertilization, and then the content in humified organic matter of the soil, it is just worth recalling the nutritional action resulting from the slow and gradual release of the nutritive elements, more synchronous to the rhythm of crop uptake, if compared to the more rapid and often unbalanced release operated by the organic matter mineralization process. From a biochemical point of view, humus plays an important role in the increase of the anion exchange capacity of the soil and organic matter stimulates soil microbial activity. From a physical point of view, the positive effects of soil organic matter on structure and its stability are very relevant, also due to the important consequences structure bears on the increase in water retention capacity of the soil aggregates. The source of organic fertilizer considered more appropriate in agriculture is manure. However, the gradual diversification of livestock activities from farming, as well as the difficulties in transportation and marketing, makes its use impractical and not economically convenient.

Furthermore, livestock wastes are increasingly used for biogas production. The use of commercial stabilized compost in rainfed crops is generally uneconomical. Then, crop residues are the only viable source capable of maintaining a minimum soil organic matter balance in dry farming systems. According to many authors, this remains a fundamental practice in cereal cultivation, in spite of the many drawbacks of the management of crop residues linked to soil tillage mechanization (especially 
in the case of abundant and coarse residues), to a depressive effect on the crop (for the removal of nitrogen by microorganisms in the case of a $\mathrm{C} / \mathrm{N}$ relationship exceeding 80-100), and to the accumulation of pathogens (Zhou et al. 2009; Ward et al. 2009).

Crop residues, in addition to the benefits arising from the presence of organic matter, perform other functions which positively improve the soil water balance. They reduce soil water evaporation thanks to their mulching action (O'Leary and Connor 1997); by increasing the ground roughness, they slow down the speed of water surface runoff; also, they contrast surface compaction especially in clay soils, thus improving the water permeability. All such factors favor soil water infiltration and storage, especially in sloping surfaces (Foley and Silburn 2002). Another consequence is the reduction of soil erosion, to the advantage of soil fertility in extreme fragile environments such as the dry environment of cereal cropping areas.

The generally low levels of soil organic matter that characterize rainfed environments contribute to a reduced availability of nutrients, principally nitrogen and phosphorus. In calcareous and red soils, phosphorus availability is further reduced by fixation process.

Regarding nitrogen, it is important to stress the role it plays in the synthesis of chlorophyll and in the assimilative processes that influence root growth and as a consequence trigger a virtuous circle of improved water and nutrient uptake along the soil profile (Kirkegaard et al. 1994). Also phosphorus participates in overall plant growth and in particular in root development; it also controls flowering and fruit setting and assimilates translocation and balances the relations between vegetative and reproductive functions of the plant. The root nutrient uptake occurs through the soil solution, and this explains the strong positive interaction between water availability and mineral fertilization. In synthesis, the availability of water favors the removal of nutrients and the efficiency of their use on one side; on the other side the availability of nutrients favors plant and root growth, and this in turn improves the removal of water and its efficiency (Zhong and Shangguan 2014). Figure 4 shows the response of durum wheat production to a combination of water and fertilization regimes in an experiment conducted by Wang et al. (2010). In particular, nitrogen fertilization increases the yield response at all water regimes by improving the utilization of water resources. As also, a higher water intake improves nitrogen use efficiency at each of the five doses of nitrogen fertilizer supplied to the crop (Wang et al. 2010).

Fertilization is therefore a technique capable of improving the agronomic response to water and enhancing, and in some ways substitute, the effect of natural water resources. However the choice of the dates and rates of supply and the choice of the type of fertilizer must be particularly accurate as a function of the water availability. Indeed, any defect in the calculation of the dose or in the choice of the abovesaid factors can reduce the effectiveness and efficiency of the fertilizer use; on the other side an excessive dose may lead to lush vegetation resulting in excessive water use, such as to result in periods of water stress, and this would be particularly dangerous in times of increased sensitivity of the crop. Therefore computation of these parameters should be based on well-defined principles of 
Fig. 4 Response of durum wheat grain yield to the soil water regime and nitrogen fertilization (redrawn from Wang et al. 2010)

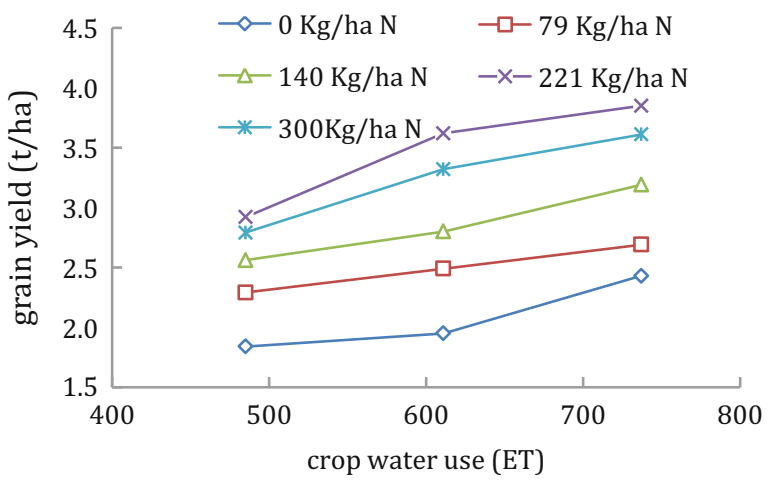

plant nutrition, soil chemistry, and chemistry of the fertilizer elements. The dose calculation from nutrient crop uptake (based on the actually obtainable yield) must be corrected by taking two major factors into account: the availability of the element in the soil and the interaction between the fertilizer and the main physical and chemical parameters of the soil $(\mathrm{pH}$, organic matter content, mineralization rate, $\mathrm{C} / \mathrm{N}$, ratio of solubilization of phosphorus, active lime content, presence of antagonist ions, etc.) (Mori and Di Mola 2012).

\section{Surface Water and Sediment Control Systems and Soil Tillage}

Cereal-growing areas in Mediterranean environments are generally characterized by rather low rainfall amounts, especially in the spring-summer. Furthermore, precipitation may further lose efficacy due to poor surface water systems management. Indeed, if the rain intensity exceeds the storage capacity of the soil, this will accumulate on its surface if the ground is flat generating flooding, with damage to the crop. On slopes losses for runoff will occur and reduced water storage will be associated with erosion and therefore with further reduction of soil fertility. Such losses will increase as the rainfall intensity and the slope steepness increase and as the soil permeability decreases.

For an efficient water and soil use, techniques to promote water infiltration into the soil and to reduce losses of surface runoff need to be used. The management of surface water systems through land remodeling and drainage design plays a key role in controlling water outflows, avoiding flooding and containing losses for runoff at the same time. In flat areas the basic element of the surface water management is a slightly convex shaping of fields generally obtained by tillage operations (local name in Italy is baulatura), which has the function of creating gentle slopes in order to drive excess water to ditches at the side of fields. In subhumid and arid environments, slopes should not exceed $1 \%$ and fields may be as wide as possible (usually over $30-50 \mathrm{~m}$ ) in order to increase the water traveling time on the soil 
surface and thus facilitate retention and water infiltration before it is intercepted by the ditch and removed from the field.

In sloping land water losses for runoff are generally higher, and surface water and sediment control is strategic for improving soil fertility. Although terracing is not economically viable for cereal crops, in these areas land surface shaping may be addressed though a simpler system, and runoff and erosion control is entrusted to ditches. Depending on the slope and soil texture, downstream ditches should be positioned before excess water reaches the threshold speed triggering erosion. In this way not only it contains the erosion, but it also directs water to flatter areas where it can be absorbed by the soil. This system is more effective if combined with techniques to facilitate soil water infiltration, like strip cropping. All agronomic techniques designed to increase permeability and water infiltration into the soil greatly improve cereal productivity. It is well known that the rate of water infiltration into the soil is mainly controlled by the distribution and size of the pores: it is directly proportional to the square of the average diameter of the pores, in particular macropores with diameter between 30 and $500 \mu \mathrm{m}$ (Pagliai 1986). A balanced presence of macropores is therefore a guarantee of good permeability. As it is known, however, as a result of the action of the water and its variations during the cycles of wetting-drying, as well as the pressure of the field machinery, the soil tends to lose structure and therefore microporosity increases. Soil tillage is one of the agronomic practices which directly improves the soil structure.

Technical progress has led to the transition from traditional and energy consuming soil tillage to conservative techniques of minimum and no-tillage. The conservative techniques impact less on soils and are capable of maintaining structure without reversing the soil layers (Holland 2004). In this context several techniques have been proposed, ranging from a simple reduction of tillage depth to subsoiling (minimum tillage) to sod seeding. Minimum tillage is achieved through machinery (harrows or plows disk) which is capable of affecting the topsoil to a depth useful only for the seedbed preparation. No-tillage is a more extreme technique based on specific seed drills equipped with disk elements which break the soil (top $5 \mathrm{~cm}$ ) and directly deposit the seed without any previous tillage (sod seeding). The energy savings can reach $70 \%$ compared to traditional tillage. The choice of traditional, minimum, or no-tillage is one of the most controversial aspects of agricultural research; effects on crops and soil conditions depend mainly on soil type and texture, crop type (depending mainly on the characteristics of the root), rainfall regime (mainly intensity), long-period tillage strategy, structural stability of the soil (in function of the organic matter content), and all other variables interacting with them. In any case, minimum tillage and sod seeding are generally less expensive and research results suggest lower $\mathrm{CO}_{2}$ emissions compared to traditional tillage.

Everything that contributes to improve the structural stability of soil aggregates has a positive effect on soil and crop behavior, mainly by increasing the stability of the macropore network and therefore in improving infiltration. In this context the contribution of organic matter and crop residues management is undoubtedly positive. The partial burial of residues with harrowing, rather than their removal from the field, is an advisable solution particularly in hilly areas. In this case, 
indeed, the partial burying of crop residues constitutes one of the few viable techniques for providing organic matter sources and promoting infiltration and water storage by increasing the soil coefficient of roughness and therefore slowing runoff. Moreover, by mulching the soil, crop residues reduce both the negative impact of raindrops on soil structure and water loss by evaporation. Infiltration is also favored, and runoff reduced by tillage, even if minimum, and by contour sowing, by increasing the soil roughness perpendicular to the lines of water flow; this slows down the water speed and thus promotes infiltration.

\section{Choice of Species, Varieties, Planting Date, and Weed and Pest Control}

The choice of crop is based on two main criteria: (a) the length and season of the growing cycle and (b) the ability of the species to keep good levels of productivity and resources use efficiency under conditions of environmental stress. Regarding the growing cycle, in the dry areas of Mediterranean environments, autumn-winter species are the most indicated, since their cycle occurs in correspondence with the time of highest precipitation amount. Among them, the most widespread are durum and spring wheat, barley, oats, and rye. Among these species, the choice falls on those which are capable to better tolerate low winter temperatures since they maintain a higher growth rate in a period which is not entirely favorable to plant physiological processes. In the most arid conditions, species which are able to tolerate water stress are preferred. Under this respect, barley, oat, and rye are more tolerant than durum and spring wheat.

More difficult is the choice of the variety that better suits the different environmental conditions. Conventional breeding and biotechnology have produced varieties which can adapt to different growing environments, such as drought-tolerant varieties and very high-yielding varieties in more favorable environmental conditions. In any case, the objective of breeding was to obtain the highest possible yield as a function of environmental conditions. The question is among the commercially available varieties, which are those that combine high production with water use efficiency? The relationships among yield potential, drought resistance, water use, and water use efficiency are not easy, since many physiological plant traits are involved in these relationships. Accurate studies on this topic were conducted by Hsiao (1993a, b) and Blum (2005). Both authors demonstrated that high productive cultivars maintain a high water use efficiency both in well-watered and in waterstress conditions compared to landrace varieties. According to Hsiao et al. (2007), over the last century plant breeders have inadvertently selected for higher water use efficiency by selecting for higher yielding ability.

Crop sowing date is also to be considered for a sustainable cereal productivity. Identifying sowing dates involves taking into account both the biological characteristics of the varieties and the rainfall and thermal trends. Sowing dates should be 
established so that the crop growing cycle is consistent with thermal and soil moisture plant physiological requirements. A useful technique can be to anticipate the time of sowing, always taking into account the specific thermal requirements of the crop. Early sowing allows to better use natural water resources resulting from rain, mainly because it reduces the time of the crop cycle falling in the springsummer period of drought.

Weed control is also a critical point for the sustainability of cereal production. The damage caused by weeds is due to competition between the cereal and weeds for the use of water, light, nutrients, and living space, with a consequent reduction in yield. In addition weeds also negatively influence the qualitative characteristics of harvested plant parts and foods, namely, reduced grain size with a lower specific weight and lower yield of semolina, contamination of grains by weed seeds, production of toxic substances (mycotoxins) as a result of fungal attack, and production of seeds containing alkaloids which can pollute flour during the process of milling.

The sustainable control of weeds should minimize the use of herbicides while safeguarding yields. To this end, priority should be given to preventive and nonchemical agronomic measures, namely:

- Rotations with weed-cleaning crops (e.g., forage crops or mechanically weeded crops).

- Soil tillage: the distribution of weed seeds and the number of seeds able to germinate along the soil depth is a function of type and depth of tillage.

- The choice of crop varieties with a phase of tillering and developing faster than the weeds; such crops are good competitors for space.

- A slightly higher sowing density allows to occupy space in such a way that weeds are controlled.

- A careful preparation of the seedbed without actually sowing stimulates weed germination. A harrowing will then be performed before the real sowing.

- Mechanical weed control in post-emergence using specific light harrow at early tillering and up to the stage of early rising controls weeds at the seedling stage.

Chemical herbicides will then be used only if the level of weeds exceeds the threshold of economic damage, but specific herbicides should be chosen according to the botanical analysis of weeds which are actually present.

Pests are also responsible of significant yield reductions, especially in monoculture systems. A sustainable pest control should keep the harmful organism populations below the density which results in economic damage, according to the ecological and toxicological aspects related to production processes. The control system should consist in preventive and direct, physical, mechanical, and/or biological strategies, and only if these are not effective in guaranteeing an acceptable containment of pests, the use of chemical plant protection means should be permitted. In this context, it is essential to create conditions that minimize the presence of harmful organisms. Pests considered harmful to cereals are many, but only a few actually have a negative effect on crop profitability. Farmers must carefully evaluate potential damage in their cultivation area, in order to make the 
most appropriate pest control choices. The main agronomic preventive means are the following: adoption of appropriate crop rotations; choice of a return time of the same crop on a given field longer than 2 years in case of heavy infection; use of healthy seed and if in doubt use of seed treatments with allowed products (this is the least invasive chemical approach); reduction of sowing density, with wider distances between rows; deep burying of straw to reduce the mass of inoculum in the soil; control of weeds as possible hosts of infectious agents; and soil water management to facilitate water drainage and avoid flooding.

\section{Precision Farming}

This management strategy is increasingly adopted. It uses data of different nature as decision support system in the planning and management of agricultural activities. The main purpose of precision farming is to adapt the inputs and farming practices to the specific local variability existing within a field. This is a new systemic management strategy, which efficiently uses different kinds of information, generated by the evaluation and interpretation of spatial variability, the management of the spatial variability in order to improve the response of crops and environmental quality, the feedback on efficiency and effectiveness of different practices and on the use of resources, and the modeling of site-specific inputs and responses. Precision farming is made possible especially through the image analysis and geo-referenced data, obtained by remote sensing, geophysical survey, and the combined use of sensors at farm level. Through the application of these technologically advanced systems, it will be possible to develop a new model of multidisciplinary agriculture, using machines equipped with "intelligent systems" in relation to the real needs of the cereal area (e.g., Geo-referential Analytic Spraying Traceability).

These techniques help farmers in their decisions, taking into account the local variability of the physical, chemical, and biological properties of the soil, as well as the timing of input application. With these precision systems, therefore, the farmer will handle cereal production treating small areas inside the farm as if they were separate surfaces, so as to equalize, optimize, and maximize the yields. With this management, in fact, resource input is balanced and optimized in order to increase the yields and reduce interventions and costs. Moreover, the environmental impact is significantly reduced, as it reduces the amount of resources used for the production. To measure and interpret the spatial variability, different technologies are used, ranging from geographic information and positioning systems, spatial statistics, and near or remote sensors. The main applications of this innovative technology will address the mapping of yield and quality of the productions, driving aids, and site-specific supply of inputs. The main results include a reduction in use and an increase in efficiency of resources such as water, fuel, and nutrients, as well as a reduction of impacts such as carbon dioxide emission. Thanks to the application of 
these technologies, an added value to the economy of the cereal sector will be reached.

Open Access This chapter is distributed under the terms of the Creative Commons Attribution Noncommercial License, which permits any noncommercial use, distribution, and reproduction in any medium, provided the original author(s) and source are credited.

\section{References}

Angus JF, van Hearwardeen AF (2001) Increasing water use and water use efficiency in dryland wheat. Agron J 93:290-298

Birard CM, Thenkabail PS, Noojipady PLY, Dheeravath V, Turral H, Velpuri M, Gumma MK, Galganakunta ORP, Cai XL, Xiao X, Shull MA (2009) A global map of rainfed cropland areas at the end of last millennium using remote sensing. Int $\mathrm{J}$ Appl Earth Observ Geoinform 11:114-129

Blum A (2005) Drought resistance, water use efficiency and yield potential—are they compatible, dissonant or mutually exclusive? Aust J Agric Res 56:1159-1168

FAO (2009) How to feed the world in 2050. High level expert forum, Rome 12-13 Oct 2009

FAO (2013) Food Insecurity in the World. FAO publications catalogue

FAO (2014a) Food Price index. www.fao.org/worldfoodsituation

FAO (2014b) Statistical book. www.fao.org/economic

Foley JL, Silburn DM (2002) Hydraulic properties of rain impact surface seals on three clay soils. Aust J Soil Res 40:1069-1083

Grassini P, Yang HS, Cassam KG (2009) Limits to maize productivity in western corn-belt: a simulation analysis for fully irrigated and rainfed conditions. Agric For Meteorol 149:1254-1265

Holland JM (2004) The environmental consequences of adopting conservation tillage in Europe: reviewing the evidence. Agric Ecosyst Environ 103:1-25

Hsiao TC (1993a) Growth and productivity of crop in relation to water use. Acta Hortic 335:137-148

Hsiao TC (1993b) Effect of drought and elevated CO2 on plant water use efficiency and productivity. In: Black JMB (ed) Interacting stress on plants in changing climate. Springer, Berlin, pp 435-465

Hsiao TC, Steduto P, Fereres E (2007) A systematic and quantitative approach to improve water use efficiency in agriculture. Irrig Sci 25:209-231

ISPRA (2014) Il consumo di suolo in Italia. ISPRA, Rapporti 195/2014

Kirkegaard JA, Gardner PA, Angus JF, Koetz E (1994) Effect of brassica break crops on the growth and yield of wheat. Aust J Agric Res 45:529-545

Mori M, Di Mola I (2012) Guida alla Concimazione. Metodi, Procedure e strumenti per un servizio di consulenza. Imago editrice s.r.l., Italy

O'Leary GJ, Connor DJ (1997) Stubble retention and tillage in a semi-arid environment: 3 response of wheat. Field Crops Res 54:39-50

Pagliai M (1986) Effetti della lavorazione e non lavorazione sulla porosità di un terreno francoargilloso investito a vigneto. Rivista di Agronomia 20:178-183

Passiura JB, Angus JF (2010) Improving productivity of crops in water limited environments. Adv Agron 106:37-75

Wang Q, Li F, Zhao L, Zhang E (2010) Effect of irrigation and nitrose application rates on nitrate nitrose distribution and fertilizer nitrose loss, wheat yield and nitrose uptake on a recently reclame sandy farmland. Plant Soil 337:325-339 
Ward PR, Whisson K, Micin SF, Zeelenberg D, Milroy SP (2009) The impact of wheat stubble on evaporation from sandy soil. Crop Pasture Sci 60:730-737

World Bank (2008). Agriculture for development. In: World development report. The World Bank, Washington, DC

Zhong Y, Shangguan Z (2014) Water consumption characteristics and water use efficiency of winter wheat under long term nitrogen fertilization regimes in northwest China. PloS One 9(6): e98850

Zhou LM, Li FM, Jin SL, Song Y (2009) How two ridges and furrow mulched with plastic film affect soil water, soil temperature and yield of maize on the semi-arid loess plateau of China. Field Crop Res 113:41-47 